\title{
TOOLS FOR EDUCATORS: STRATEGIES AND IDEAS FOR FACILITATING ONLINE GROUP WORK USING PROJECT MANAGEMENT PRINCIPLES.
}

\author{
Dalia Hanna \\ Ryerson University, Toronto (CANADA) \\ dhanna@ryerson.ca
}

\begin{abstract}
Group work can be used as an effective tool to help students learn from each other, build community and engage with the course content. The key to the success of a group is in the planning and understanding of the purpose of the work needed. The Technology Enhanced Collaborative Group Work (TECGW) indicated through their research on group work that the way in which instructors facilitate a group project has a major impact on the success of the group. Many educators incorporate group work in their courses, but they may not provide the necessary support to students working in these groups; consequently, students get discouraged, and may decline working in groups. In the online learning environments, with the elimination of physical presence, it is necessary to bring students simultaneously to collaborate on various activates of the course to enhance their engagement with each other, the content and the instructor. As technology plays a vital role in online environments, instructors need to develop strategies for students could help them in planning, collaborating and communicating, synchronously and asynchronously, effectively within a group.

Project management concepts could effectively be utilized to help in facilitating students' group work. This paper, introduces effective strategies that will help instructors in facilitating group work by providing tools that students could utilize to understand and define their roles in the group. Additionally, the paper will introduce practices in creating group work assignments, supporting students in groups and enhancing communication among students in online environments. The paper provides some practices in using Web 2.0 tools that could facilitate the production of group work, and how these tools could facilitate learning among students working together on face-to-face and online courses.
\end{abstract}

Keywords: Group Work, Project Management, Collaboration, Online Learning, Technology, Virtual Teams, Instructional Design, Web 2.0, Wikis, Google Drive, Blogs, Assessment, Rubrics.

\section{INTRODUCTION}

Group work in higher education could prepare students to enter the workplace by providing them with the skills necessary in a team based environment. Through group work, students work collaboratively to solve problems, listen to other students' ideas and respect alternative opinions from those with different backgrounds and life experiences [1]. Employers are asking for multi-skilled graduates who could work in teams, solve problems and are self-directed; additionally, they are looking for graduates with strong interpersonal and communication skills [2].

\subsection{Benefits of Group Work}

In higher education, there is a growing need to create assignments and opportunities for students to work in groups to prepare them for the workforce [3]. Research indicates that the success of these groups depends on how instructors facilitate group work [4].The National Survey on Student Engagement (NSSE) identified active and collaborative learning as one of five benchmarks of effective educational practice. The report states that students learn more when they are strongly involved in 
their education and are asked to think about and apply what they are learning in various settings [5]. Collaborating with others in solving problems or mastering difficult material prepares students to deal with the messy, unplanned problems they will encounter daily, both during and after their graduation [5]. In online learning environments, collaboration could help students in developing critical thinking skills, co-development of knowledge and create a community of learners that could help them in gaining additional skills [6].

\subsection{Challenges of Group Work}

Students may face some challenges while working in groups in both the face-to-face and online environments. In addition, there is a perception among students that it is easier to work alone on a project and that it creates more workload on students to work in groups. Some of the common problems that the students indicated are the difficulty in communicating with group members, conflicts, do not know how to start [7], and the absence of leadership role. Students collaborating in the online learning environments may encounter the same challenges that they may face in the face-to-face environments; being at a distance may increase these challenges. For example, there could be difficulties to communicate due to technical problems and the diversity of written language [8].

\section{WHY PROJECT MANAGEMENT?}

One method of helping students work effectively within groups is through the application of project management techniques. According to The Guide to the Project Management Body of Knowledge (PMBOK), a project "is a temporary endeavor undertaken to create a unique product, service or result" [9] (p. 5). Projects developed by students in groups provide unique deliverables and the project is temporary in nature [10].

Project Management is "the application of knowledge, skills, tools and techniques to project activities to meet project requirements." [9] (p.6). Project management is accomplished through the application and integration of the project management processes of, initiation, planning, executing, monitoring and controlling, and closing [9]. Both the work in groups and the design of the assignments could utilize the project management concepts. The monitoring and controlling phase represents the role of the instructor in monitoring student's work in groups.

\subsection{Project Management Tools}

The instructor's facilitation role is critical to the success of group work; the instructor could serve as coach, moderator and advisor [2]. Before the beginning of the projects, instructors need to clearly define the purpose of the project, define roles for students and help students in understanding how to deal with conflict in groups. The following are tools and ideas that instructors could utilize and provide for their students to help them in the process and to achieve the desired outcomes.

\subsubsection{The Charter}

The charter is the document that lists the initial requirements, expectations and needs [9]; it also serves as the reference point for the project's objectives, deliverables and process [11]. Therefore, the charter in students group work could serve the same purposes; the document should clearly states the group goals and objectives the roles and responsibilities of each student, communication methods, and strategies to use when conflict arise among students. To help students in group in developing the charter, the instructor could provide a template before the start of the project; he/she could then explain the need to have a charter for each group and how students could collaboratively develop the charter. Appendix (A) is a template of a charter [12] that instructors could send to their students; it could be posted in learning management systems, as a Google Document or distributed as a hard copy in class. Then, students work together in complementing the charter and submit it back, as a group, to the instructor. After reviewing each group's charter the instructor could modify or add comments to the charter, and return to students with personalized and appropriate feedback.

\subsubsection{Work Breakdown Structure}

The Work Breakdown Structure (WBS) is another tool that instructor could provide for their students. WBS are organizational charts to help mapping all tasks required in the project [13]. In addition, WBS help to divide the project tasks into smaller and manageable deliverables [9]. After clearly articulating the objectives of the project in the charter; students could break down these objectives into smaller 
tasks; after, they define timelines, responsibilities and interdependency for each task. Fig. 1 provides an example of a WBS.

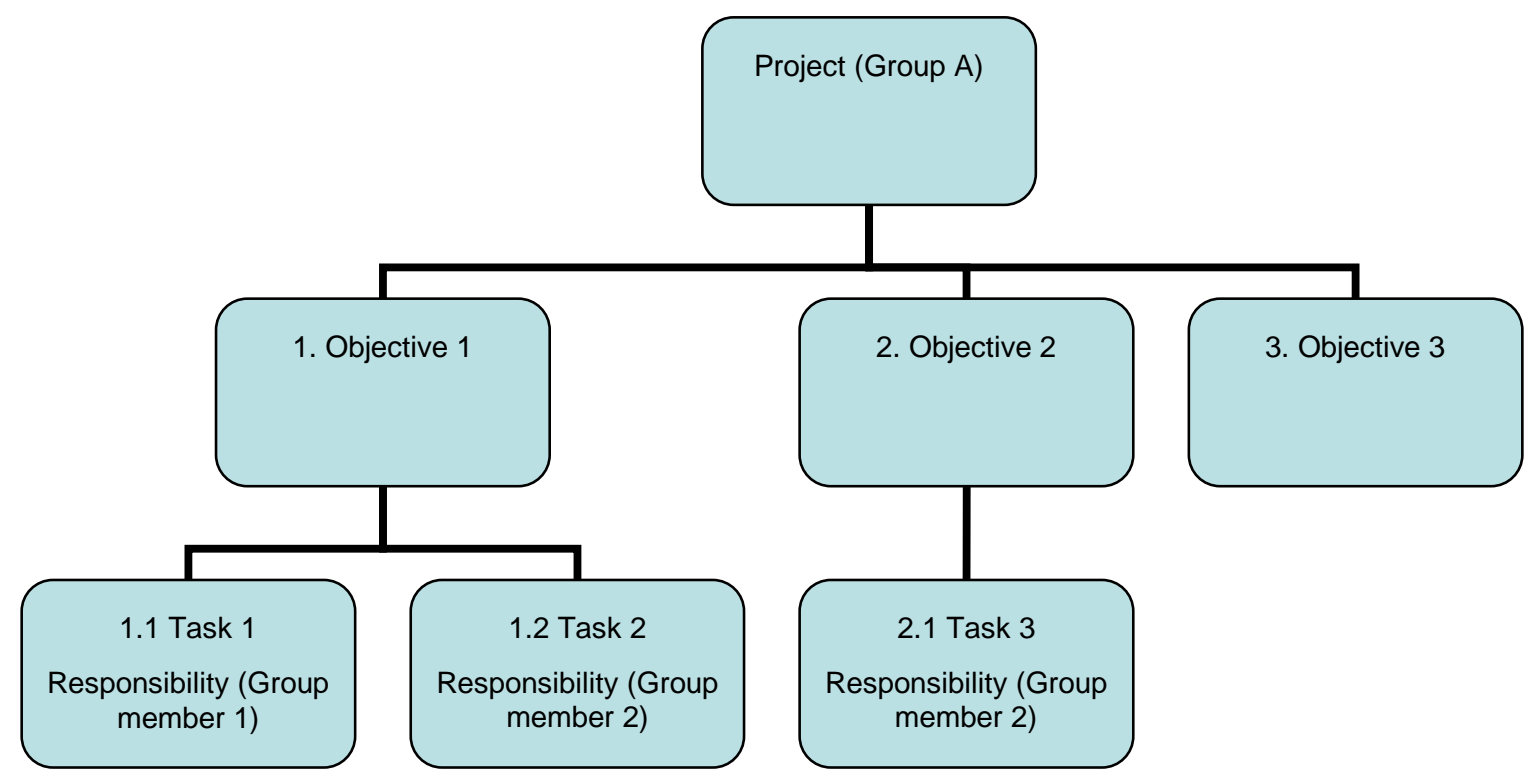

Fig. 1 An Example of a Work Breakdown Structure

\subsubsection{Leadership Role}

In group work, some students are reluctant in taking the lead and some jump in and take the lead without giving a space for other students' contribution. Many of the conflicts and problems in group work are related to group meetings. In the face-to-face environment students may not attend meetings, may waste time by discussing out of topic issues and may leave the group. In the online environment, culture differences, technology tools and time zones may affect students' communication and collaboration.

Effective groups must be able to decide if they need a leader and, if so, how to select their leader and what the leader's job will be. One possible suggestion for students is to use self-managed work teams [14]. In self-managed work teams, the leadership role rotates, with a different member chairing weekly meetings. Other roles in a group meeting could be note taker and time keeper. The leader is responsible for setting an agenda and outcomes for the meeting, and for sending them to members ahead of time. The leader is also responsible for encouraging team members and keeping the group on track.

\subsubsection{Forming Groups}

The project groups can be either student-formed or instructor-assigned. Students often prefer forming their own groups; they perceive that this will be more productive as it is easier to agree and communicate. However, instructors often want more control and they may form students based on their skills and the associated tasks embedded in the assignment. When deciding which method to use, keep in mind that although students-selected groups perceived they produced higher-quality work, the actual grades assigned to the group projects did not differ between group formation conditions [15]. What's more important is that students in groups, no matter what their makeup, need to learn how to organize the work and communicate with each other.

Some instructors form groups based on feedback from students about their skills and preferences. After explaining the project requirements, instructors may to submit one-minute-paper in class indicating there proffered roles in the group and the reasons for selecting this role. In online environments, students could use the discussion forum areas to submit the same information or the instructor may send an electronic survey to collect information from each students. After, instructors could divide the groups based on the input they collected from students. 


\section{ASSESSING GROUP WORK}

The instructor's facilitation role is critical to the success of group work; the instructor could serve as coach, moderator and advisor [2]. Equally important, is how instructors design the assignment, communicate expectations and develop guidelines associated with group assignments [3].

In Online learning environments, evaluation of students, in general, could be challenging; assignments in the online environment have to follow the basic students' assessment principles [6]. It has to be student-centred, formative, instructor-directed, ongoing and context-specific [6].

\subsection{Designing the Assignments}

One of the effective principles that should guide the development of online assessments for group projects is to include clear grading rubrics to assess the students' work through the project including their involvement in the discussions, assignments and the collaboration component itself [6]. Further, well designed assessment should equally assess individual contribution as well as the accomplishments of the group as a whole [3]. Instructors could utilize the use of project management processes in the design of assignments. During the initiation phase, the instructors explain and post the project requirements; assign roles and provide a template for the charter. Students in this phase may indicate their preferences, start forming groups, fill and submit the charter collaboratively. Throughout the planning phase instructor review the charter and provide feedback, this may be a graded activity, and students start planning for their projects, and completing the work breakdown down structure sheet. As students executing the tasks associated with the project, preparing drafts and attending meeting, instructors need to monitor the process and the development of the project by asking for drafts and notes [4]. Instructors should use a feedback mechanism which should have been clearly explained to the students before the start of the project. The feedback could include, online comments, meeting with group, and feedback on drafts and notes for eth project. Finally, the students are ready to submit their final product and may present in class or online. Table 1 provides a summary of the assignment phases and the associated activates and outcomes through the five project management process.

\section{Table 1}

Designing Assignments and its Associated Outcomes and Activates Based on Project Management Processes

\begin{tabular}{|c|c|c|}
\hline Process & Assignment (Instructor) & $\begin{array}{c}\text { Outcomes and Activities } \\
\text { (Student) }\end{array}$ \\
\hline Initiation & $\begin{array}{l}\text { Hand in the assignment to students } \\
\text { with clear goals (maybe roles). } \\
\text { Post the charter. }\end{array}$ & $\begin{array}{l}\text { Forming groups ( e.g. One } \\
\text { minute paper to indicate } \\
\text { skills, preferences or } \\
\text { random) }\end{array}$ \\
\hline Planning & $\begin{array}{l}\text { Review contracts and adjust the } \\
\text { groups if needed - Graded }\end{array}$ & $\begin{array}{l}\text { The contract with defined } \\
\text { roles for each student }\end{array}$ \\
\hline Executing & $\begin{array}{l}\text { Feedback on the draft report - } \\
\text { Graded (each student) }\end{array}$ & $\begin{array}{l}\text { Meetings - Draft report } \\
\text { based on research }\end{array}$ \\
\hline $\begin{array}{l}\text { Monitoring and } \\
\text { Controlling }\end{array}$ & $\begin{array}{l}\text { Monitor communication among } \\
\text { students, request minutes of } \\
\text { meetings and provide personalized } \\
\text { feedback }\end{array}$ & $\begin{array}{c}\text { Peer review and } \\
\text { comments among groups }\end{array}$ \\
\hline Closing & $\begin{array}{c}\text { Final grade (Independently and as a } \\
\text { group) }\end{array}$ & Present final project \\
\hline
\end{tabular}

\subsection{Feedback}

Timely and frequent feedback is imperative to the success of online group work. Students need to know what they have done well and what needs improvement or be modified; this could also motivate students to use the feedback and utilize it to improve their work as they develop their projects, and 
prepare them for future assignments as well [16]. Moreover, Pallof and Pratt (2005) explained that in virtual learning environments, it is important that instructor prepare student to use peer and self evaluations effectively. Some students may have concerns and fears but instructors need to encourage students to use peer evaluations by explaining that is it should be constructive and promote improvements. Instructors could explain to their students that they need to be careful when writing a feedback to a peer. For example, they need to use short paragraphs, read the feedback few times before sending it to peers and that they need to maintain professional levels of communication among each other [6].

\subsection{Expectations and Rubrics}

Timely and frequent feedback is imperative to the success of online group work. Students need to know what they have done well and what needs improvement or be modified; this could also motivate students to use the feedback and utilize it to improve their work as they develop their projects. Rubrics are scoring guides and checklists for pre-established performance criteria [17]. By using rubrics in evaluating assignments, instructors could provide evidence of learning patterns by applying the approved criteria [18]. These patterns identify students' strength and weakness which help institutions to update the curriculum, review the instructional design process and re-visit the learning practices [18]. Students could use rubrics as a formative assessment tool to assess the progress of their work [19]. Additionally, it could help students in achieving higher performance levels by improving the quality of the assessment based on the criteria and descriptors listed in the rubric [19]. Simonson, Smaldino, Albright and Zvacek (2012) explained that continuous formative evaluation can help inform the students about their progress towards their goals and with help from the instructor, students can shape their ways towards accomplishing their goals [20]. For instructors, rubrics could provide standardized assessment scheme, which could help the instructor to assign grades quickly and objectively [19].

Davis (1993) explained that, in group work, instructors should assign group tasks that allow for a fair division of labor and require interdependence at the same time [21]. Therefore, rubrics designed for group work need to be simple yet comprehensive to provide clear expectations to students; a rubric should indicate descriptive performance measures for both the group and the individual students [6]. "If rubrics are linked to course expectations and students are directed to use them for assessment of themselves and their peers, students will end the course with a clear picture of their performance" [6] (p. 44).

The University of Colorado Denver provide an online tutorial that could help instructors in building effective rubrics, the link to the online tutorial is ( http://bit.ly/181WNmL ).

\section{COMMUNICATION}

Online education can be very text-driven; therefore, there is a need to integrate diverse communication strategies into online courses to engage and maintain students as active participants. Many factors affect the message sent among a sender and a receiver at a distance; there difference in personalities, cultures, judgment, values and emotions [14]. For this reason, instructors are encouraged to incorporate teaching and learning strategies that could promote students' engagement and interaction with the content, their peers and the instructor [22].

\subsection{Communication Tools}

In the online learning environments, instructors need to select the appropriate technologies that could help students in demonstrating their competences [20]. To illustrate, students working in groups could make use of the technology tools to communicate and present their projects.

Synchronous communication tools are technology tools that students could use if they are located at a distance and want to connect at the same time. Examples of synchronous tools are video conferencing and chat tools like Skype and Google Drive applications. Asynchronous communication tools are tools that students could use when they are located at a distance and at different time, some examples are web 2.0 tools like blogs and Wikis, and discussion forums in a learning management system. Instructors then need select these tools based on the objectives and the associated outcomes be able to choose a proper tool and function. 


\subsubsection{Blogs}

Blogs are a form of a website; blogging or web blogging is a form of writing online journals [20] with the ability to post comments and replies based on the various posts on the blog. Students could use blogs to build on each others' ideas, reflect on their learning experience or report activates [20]. There are many free blog providers in the internet like Blogger.com and Wordpress.com. Additionally, some learning management systems has blog tools embedded in the course; however, access to these blog tools are restricted to students in class. While the blog on the Internet are open to public.

\subsubsection{Wikis}

Wikis are another form of websites; the term is derived from the Hawaiian word wiki which means quick [20]. Wikis could be used as a synchronous and asynchronous tool. Wikis could be a perfect tool for online collaborative projects; for example, each student could build a page on eth website; then, students could edit each others' work, and they could build a common page for resources based on their individual research. Through a wiki and proper access, instructors could examine the work of each student, post comments and check the revisions made throughout the project. This will give instructors a accurate view of the collaboration aspects of the project and could verify the comments and grades students gave to each other.

\subsubsection{Google Drive Applications}

A suite of applications that includes Google Docs, Presentation, Spreadsheet, Forms, and Drawings. Google Drive allows instructors and students create, collaborate, and store their work in the cloud, for use in any time or place [23]. The charter could be posted on as a Google document and students could collaboratively complete it. Through Google Docs instructors could view each ones contribution and provide quick feedback to the group. Additionally, instructors could examine the revision history of the document. Students could use the presentation application to collaborate on designing and developing their final project; once completed, they could send the students in class the link to the presentation and each could post a comment or provide a peer grade. Google drive applications could be used as an asynchronous and synchronous communication tool as there is a built in chat tool that could enable students to connect at the same time.

\section{SUMMARY}

Due to their past experience, students working in groups may perceive that group projects are hard and in-effective. Therefore, instructors need to indicate the reason for group work, provide clear expectations and help students by providing tools and support to guide them throughout the project. Additionally, instructors should develop a feedback mechanism that could help students in understanding the criteria, their roles and required performance levels. Project management processes could help both the students and instructors, in being organized. Some helpful tools are: group charter, work breakdown structure and rubrics. In online learning environments, group work could enhance the students' learning experience through active, engaging, and effective interactions and activities. Students at a distance may face some challenges in communicating throughout the project; for this reason, it is recommended that instructors incorporate technology tools that support their learning objectives and could facilitate students' communication. 


\section{REFERENCES}

[1] Kuh, G.D. (2008). High-Impact Educational Practices. Association of American Colleges and Universities. Retrieved from http://www.aacu.org/leap/hip.cfm

[2] Victoria University of Wellington. (2004). Group work and group assessment. Retrieved from http://www.utdc.vuw.ac.nz/resources/guidelines/groupwork.pdf

[3] Mclnnes, J. R., \& Devlin, M. (2002). Assessing learning in Australian universities: Ideas, strategies, and resources for quality student assessment. Retrieved from http://www.cshe.unimelb.edu.au/assessinglearning/docs/AssessingLearning.pdf

[4] Engage. (2012). Technology-Enhanced Collaborative Group Work. Retrieved from http://engage.wisc.edu/collaboration/

[5] National Survey of Student Engagement (NSSE). (2009). Assessment for improvement: Tracking student engagement over time-Annual results 2009. Bloomington, IN: Indiana University Center for Postsecondary Research.

[6] Palloff, R. M., Pratt, K. (2005). Collaborating online: Learning together in community. San Francisco, CA: John Wiley and Sons Inc.

[7] The University of Queensland. (2012). Problems associated with group work. Retrieved from mhttp://www.uq.edu.au/student-services/Problems+associated+with+group+work.html

[8] Ragoonaden, K. \& Bordeleau, B. (2000). Collaborative learning via the Internet. Educational Technology \& Society, 3(3). Retrieved from http://www.ifets.info/others/journals/3 3/d11.html

[9] Project Management Institute. (2008). A guide to the project management body of knowledge. Newtown Square, PA: Project Management Institute Inc.

[10] Williams van Rooij, S. (2011). Instructional design and project management: complementary or divergent? Education Tech Research Dev, 2011(59). pp. 139-158.

[11] University of Calgary. (n.d.). Project Charter. Retrieved from http://www.ucalgary.ca/research/files/research/Sample\%20Project\%20Charter.pdf

[12] Hicks, C. (2011). Guiding group work: Activities to maximize student learning from group projects. Teaching Innovation Projects. 1(1), Article 6.

[13] Russell, L. (2000). Project management for trainers. Alexandria, VA: ASTD Press.

[14] Verma, V. K. (1997). Managing the project team. The human aspect of project management (v. 3). Newtown, PA: Project Management Institute

[15] Hilton, S., \& Phillips, F. (2010). Instructor-assigned and student-selected groups: A view from inside. Issues in Accounting Education, 25(1), 15-33.

[16] Betts, K. S. (2008). Online human touch (OHT) instruction and programming: A conceptual framework to increase online student engagement and retention in online education, Part 1. Journal of Online Learning and Teaching, 4(3), pp. 399-418.

[17] Mertler, C. A. (2001). Designing scoring rubrics for your classroom. Practical Assessment, Research \& Evaluation, 7(25).

[18] Maki, P. L. (2004). Assessing for learning: Building a sustainable commitment across the institution. Sterling, VA: The American Association for Higher Education.

[19] Reddya, Y. M., \& Andrade, H. (2010). A review of rubric use in higher education. Assessment and Evaluation in Higher Education. 35(4), 435-448.

[20] Simonson, M., Smaldino, S., Albright, M., \& Zvacek, S. (2012). Teaching and learning at a distance: Foundations of distance education (5th ed.). Boston, MA: Pearson.

[21] Davis. (1993). Davis B. G. (1993). Collaborative Learning: Group Work and Study Teams. In Tools for Teaching. Retrieved from http://teaching.berkeley.edu/bgd/collaborative.htm

[22] Dashaw, B., \& Lee, R. (2011). Designed learner interactions in blended course delivery. Journal of Asynchronous Learning Networks. 15(1), 68-76

[23] Google. (2013). Google Drive. Retrieved from https://drive.google.com/ 


\section{Appendix (A) \\ Group Charter/Contract}

What is/are the deliverables of our group? (Goals should be SMART: Simple, Measurable, Attainable, Results oriented, Time bound)

- Check to see if the goals are similar to the ones that the instructor provided for the group.

- In online document list bulleted statements

What are our pressures? (ex: Money? Time?)

- Have they listed all pressure or not, are the pressure realistic

How will we deal with/compensate for our pressures?

- What are their strategies to overcome the pressures, for example: If time is a pressure, how will they plan to resolve this problem (virtual meetings, Skype, discussion board)

What are the strengths of our group and its members?

The instructor should look at a variation of skills that could contribute to the success of the group and the project, is there enough diversity (if diversity is needed), is there any overlap?

\begin{tabular}{|l|l|}
\hline Group member & Strength(s) \\
\hline & \\
\hline & \\
\hline & \\
\hline & \\
\hline
\end{tabular}

Operating Guidelines:

How will we capitalize on the strengths of each member?

In this section it is recommended to give the students examples of responsibilities related to the project, this will help students in understanding the various roles. They then list how they can contribute to the specified goals.

What communication tools will we use to communicate? (Email? Facebook? What is the maximum expected response time?)

If Skype, students all need to have accounts and share their Skype id... For email, what is the frequency and when to expect a response

What process will we follow if someone does not live up to the responsibilities? Be specific.

- Try to examine the reasons and try to find a solution among the group.

- If a student drops out the group who will take over and continue with the project

- Inform the instructor with the situation

Signatures

\begin{tabular}{|l|l|l|l|}
\hline Member 1 & Member 2 & Member 3 & Member 4 \\
\hline & & & \\
\hline
\end{tabular}

You might not need signatures for online students, but should request an acknowledgment that they all agree to the charter. This could be done by email to you and to the group members.

Adapted from Hicks, C. (2011). Guiding group work: Activities to maximize student learning from group projects. Teaching Innovation Projects. 1(1), Article 6. Retrieved from:

http://ir.lib.uwo.ca/tips/vol1/iss1/6 